\title{
Water based-ionic liquid carbon dioxide sensor for applications in the food industry
} \author{
Luis Fermin Capitan-Vallvey ${ }^{\mathrm{a}}$ \\ ${ }^{a}$ ECsens, Department of Analytical Chemistry, University of Granada, Granada, 18071, Spain \\ ${ }^{\mathrm{b}}$ Insight, Centre for Data Analytics, National Centre for Sensor Research, Dublin City University, Dublin 9, Ireland \\ c School of Biotechnology, Dublin City University, Dublin 9, Ireland
}

Isabel M. Perez de Vargas-Sansalvador ${ }^{\mathrm{a}}{ }^{\mathrm{b}}, *$, Miguel M. Erenas ${ }^{\mathrm{a}}$, Dermot Diamond ${ }^{\mathrm{b}}$, Brid Quilty $^{\mathrm{c}}$,

\section{A R T I C L E IN F O}

\section{Article history:}

Received 9 December 2016

Received in revised form 5 June 2017

Accepted 7 June 2017

Available online $\mathrm{xxx}$

Keywords:

Carbon dioxide sensor

Gas sensor

Ionic liquids

Optical sensor

Smart packaging

Food spoilage

\begin{abstract}
A B S T R A C T
A new water-based sensor for carbon dioxide containing an ionic liquid is presented. The sensor is based on the acidity of the $\mathrm{CO}_{2}$ molecule. The sensor incorporates an ionic liquid in the matrix, which enhances $\mathrm{CO}_{2}$ solubility, and minimising the response and recovery times of the sensor. The entire concentration range $(0-100 \%)$ of $\mathrm{CO}_{2}$ in water has been studied. The sensor is more sensitive at low $\mathrm{CO}_{2}$ concentrations as is usual in this kind of optical sensor. As the sensor is intended for smart food packaging, one of the most important characteristics is stability, and this has been studied under different conditions of light, temperature and relative humidity. The sensor was found to be stablef or more than 14 days, which is the period of use for the intended application.

Pork chops were packed at $4{ }^{\circ} \mathrm{C}$ and the production of $\mathrm{CO}_{2}$ studied in conjunction with total bacterial counts over a period of 14 days. The results show that the concentration of $\mathrm{CO}_{2}$ dioxide increases in time, in correlation with bacterial counts. As the threshold of $\mathrm{CO}_{2}$ content for human consumption of this meat is $20 \%$, the sensor has been optimised for detection around this concentration.
\end{abstract}

(C) 2017

\section{Introduction}

The importance of $\mathrm{CO}_{2}$ is evident in different fields such as environmental [1], clinical [2], biological [3] and industrial [4,5]. In recent years, the determination of $\mathrm{CO}_{2}$ has attracted great interest, along with other gases such as oxygen and nitrogen in confined spaces [6]. This is especially interesting for the control of insect pests in art and archaeological items in museums, through controlled atmosphere treatment (CAT), in which $\mathrm{CO}_{2}$ gas is used to displace oxygen within a sealed enclosure to a percentage low enough to kill all stages of the insect life-cycle [7]. The treatment time is typically four-weeks, over which it is imperative that the $\mathrm{CO}_{2}$ does not fall below $60 \%$, and therefore the strict control of $\mathrm{CO}_{2}$ level is essential during that period of time. The use of climate chambers with modified atmospheres is becoming popular among art museums and collections to avoid the deterioration of items [8]. Controlled Atmosphere Storage is also used in food industry, for example for fruits and vegetables and has great importance in extending their postharvest life [9].

Another example of the importance of $\mathrm{CO}_{2}$ in confined environments is tracking of $\mathrm{CO}_{2}$ in modified atmospheres of packaged food and particularly meat products. In a normal environment, meat products are packed in a modified atmosphere, which typically consists of

\footnotetext{
* Corresponding author at: University of Granada, ECsens, Department of Analytical Chemistry, Granada 18071, Spain.

Email address: isabelpdv@ugr.es, isabelpdv@hotmail.com (I.M.Perez de
} Vargas-Sansalvador) a mixture of nitrogen, oxygen and $\mathrm{CO}_{2}$ which has been optimised [10] to expend the lifetime of the food. This modified atmosphere inhibits the early deterioration of meat products, allowing for longer shelf life, maintaining freshness, colour stability and the inhibition of microbial spoilage $[11,12]$

The $\mathrm{CO}_{2}$ levels inside meat packages can be used as indicator of freshness. A change in $\mathrm{CO}_{2}$ concentration during storage is a clear indication that bacteria are growing inside the container and/or the package is not properly sealed and the modified atmosphere has been compromised. However, a non-destructive method for determining the $\mathrm{CO}_{2}$ concentration within such packages has not, as yet, been reported.

In order to integrate smart materials as sensor systems in packaging, they need to be compatible with printing technology for mass production used in the industry, as this is required to maintain low unit-cost relative to the value of the food product. In addition, printing is an attractive option for sensor fabrication due to ease to use, accuracy and precision, reliability, and alignment with food safety requirements. The major restrictions that impede the use of current sensors in food are: instability of chemistry used, toxicity of sensor materials, difficulty of integration into food packages at an acceptable cost, and difficulty of detection [13]. Recently it has been reported by Puligunda et al. that "the development of efficient $\mathrm{CO}_{2}$ sensors that can intelligently monitor the gas concentration changes inside a food package and specific to food packaging applications is essential" [14].

Most existing $\mathrm{CO}_{2}$ optical sensors are based on absorption by the gas at the $4.26 \mu \mathrm{m}$ IR absorption band [15]. However, there are two 
important drawbacks to this approach: (i) the strong interference by water vapour and (ii) the cost of the sensors. In recent years, there have been many publications on $\mathrm{CO}_{2}$ sensor development based on absorbance [16-18] or luminescence [19,20] in combination with acid-based indicators, but none of these sensors have been investigated for application in smart packaging technologies. Optical $\mathrm{CO}_{2}$ sensors based on the acidity of this molecule are normally solvent-based sensors, but in the food packaging industry these suffer from the drawback of long-term instability, arising from decomposition of the commonly used quaternary ammonium hydroxide derivatives $[18,21]$. In this work, we have avoided using these compounds. Instead, water based sensors have been prepared using meta cresol purple sodium salt as the indicator, glycerol as plasticizer and sodium hydrogencarbonate as buffer in a matrix of hydroxyethyl cellulose. In this way, the lifetime is increased and also this composition creates an easily printable ink. To our knowledge, this type of water based sensor for $\mathrm{CO}_{2}$ has been reported only once previously, by Mills et al. [16]. However, in an additional development, we have included ionic liquids (IL) in the matrix, making the sensor more selective to $\mathrm{CO}_{2}$ than other gases due to its higher solubility. Ionic liquids have been used previously in solvent based $\mathrm{CO}_{2}$ sensors [22,23]. In the first case, the sensors prepared were liquid sensors[22], and could not be used as a smart material for the food industry. In the second case [23], the IL was used together with 1-hydroxy-3,6,8-pyrenetrisulfonate (HPTS) and tetraoctylammonium hydroxide (TOAOH) in a matrix of ethyl cellulose to generate a fluorescence-based analytical signal. However, these sensors are highly difficult to implement in the food industry because (i) they need be spread over the substrate in the basic form and (ii) the system of detection is not a simple device, making it difficult to implement as a food freshness indicator. In contrast, the sensing chemistry for $\mathrm{CO}_{2}$ studied in this paper is based on plastic solid-state sensor membranes that respond to the acidity of the $\mathrm{CO}_{2}$ molecule. In this system, an acid-base indicator (MCP) is included in $\mathrm{a} \mathrm{CO}_{2}$ permeable membrane containing hydrogen carbonate as an internal buffering system to (i) ensure the indicator is predominantly initially the deprotonated form and the basic form is stabilised as a hydrated ionic pair and (ii) to enable the uptake of $\mathrm{CO}_{2}$ from the atmosphere by forming a hydrogencarbonate buffer. The change in the position of the acid-base equilibrium by $\mathrm{CO}_{2}$ in the membrane is transduced into a change in colour/absorbance of the indicator immobilised in the membrane.

The gaseous $\mathrm{CO}_{2}$ dissolves in water according to the following equations:

$$
\begin{aligned}
& \mathrm{CO}_{2}(g) \leftrightarrows \mathrm{CO}_{2}(l) \quad \mathrm{K}_{\mathrm{D}}=3.3 \cdot 10^{-2}(1) \\
& \mathrm{CO}_{2}(\mathrm{l})+\mathrm{H}_{2} \mathrm{O} \leftrightarrows \mathrm{H}_{2} \mathrm{CO}_{3} \quad \mathrm{~K}_{h}=2.6 \cdot 10^{3}(2) \\
& \mathrm{H}_{2} \mathrm{CO}_{3}+\mathrm{H}_{2} \mathrm{O} \leftrightarrows \mathrm{HCO}_{3}^{-}+\mathrm{H}_{3} \mathrm{O}^{+} \quad \mathrm{K}_{1}=1.72 \cdot 10^{-4}(3) \\
& \mathrm{HCO}_{3}^{-}+\mathrm{H}_{2} \mathrm{O} \leftrightarrows \mathrm{CO}_{3}^{2-}+\mathrm{H}_{3} \mathrm{O}^{+} \quad K_{2}=5.59 \cdot 10^{-11}(4)
\end{aligned}
$$

A change in the $\mathrm{pH}$ of the medium is detected by a $\mathrm{pH}$ indicator HIn present in the same medium that changes colour:

$$
\begin{array}{lc}
\mathrm{HIn}+\mathrm{H}_{2} \mathrm{O} \leftrightarrows & \mathrm{H}_{3} \mathrm{O}^{+}+\mathrm{In}^{-} \\
\text {colour } 1 & \text { colour } 2
\end{array}
$$

The $\mathrm{pKa}$ of the indicator selected should be adequate to change the position of the equilibrium in the presence of protons generated by the dissociation of carbonic acid originating from the $\mathrm{CO}_{2}$ (Eq. (3) above). It has been reported that the preferred $\mathrm{pK}_{\mathrm{a}}$ should be around 7.0-8.3 and for this reason, the appropriate $\mathrm{pH}$ indicators used to sense $\mathrm{CO}_{2}$ include $\alpha$-naphtholphthalein [29], thymol blue, and bromo thymol blue [30].
To the best of our knowledge, this is the first report of a water based colorimetric $\mathrm{CO}_{2}$ sensor for use in smart food packaging that has unique advantages arising from an ionic liquid in the matrix.

\section{Experimental}

\subsection{Reagents and materials}

2-Hydroxyethyl cellulose (HEC, average Mv 90,000), meta-cresol purple sodium salt (MCP), glycerin, sodium hydrogencarbonate and the ionic liquid 1-ethyl-3-methyl-imidazolium chloride were all sourced from Sigma-Aldrich Química S.A. (Spain). For microbiology buffered peptone water (LAB046), maximum recovery diluent (LAB103), Plate Count Agar (PCA) LAB149, pseudomonas agar base (LAB108), violet red bile agar (VRBA) (LAB031) all from LAB M Heywood (Lancashire, UK) were used. All aqueous solutions were made using reverse-osmosis quality water (Mili-RO 12 plus Milli-Q station from Millipore, conductivity $18.2 \mathrm{M} \Omega \mathrm{cm}$ ).

Pork boneless chops were bought from the Butchers Shop (Omni shopping centre, Santry, D9, Ireland) and high barrier bag material BB3055 specific for meat products were obtained from Sealed Air (Seville, Spain).

Additionally an homogeniser Stomacher AGB Scientific Ltd, (Dublin Ind Est Dublin 11 Co. Dublin, Ireland), a heat sealer PFS-300MM Electric Impulse Sealing Machine C. (Media w.s. trade sl Barcelona, Spain) and a CheckPoint - Handheld Gas Analyzer $\left(\mathrm{O}_{2} / \mathrm{CO}_{2}\right)$ Dansensor A/S (Rønnedevej 18, DK-4100 Ringsted, Denmark) to $\mathrm{O}_{2}$ and $\mathrm{CO}_{2}$ measurements inside meat packages, were used.

The standard mixtures for instrument calibration and characterization were prepared using $\mathrm{N}_{2}$ as the inert gas by controlling the flow rates of the different high purity gases $\mathrm{CO}_{2}$ and $\mathrm{N}_{2}$, entering a mixing chamber using a computer-controlled mass flow controller (Air Liquid España S.A., Spain) operating at a total pressure of 760 Torr and a flow rate of $500 \mathrm{~cm}^{3} \mathrm{~min}^{-1}$.

To produce different humidity conditions (from 14 to $100 \% \mathrm{RH}$ ), a CEM system was used. This system consists of a mass flow controller for measurement and control of the carrier gas flow (mixtures of $\mathrm{N}_{2}$ and $\mathrm{CO}_{2}$ ), a mass flow meter for liquids (MiniCoriflow) with a range of $0.4-20 \mathrm{~g} / \mathrm{h}$ of liquid (water in this case), and a CEM 3-way mixing valve and evaporator for control of the liquid source flow and mixing the liquid with the carrier gas flow resulting in total evaporation. Moreover, it contains a temperature-controlled heat-exchanger to add heat to the mixture to produce complete evaporation of the liquid $\left(100^{\circ} \mathrm{C}\right.$ was selected for water).

\subsection{Preparation of $\mathrm{CO}_{2}$ sensing membranes}

Sensing membranes for $\mathrm{CO}_{2}$ were prepared from a cocktail containing $12.5 \mathrm{mg}$ of HEC, $1.4 \mathrm{mg} \mathrm{MCP}, 2.25 \mathrm{mg} \mathrm{NaHCO} 3$ and $37.5 \mathrm{mg}$ glycerin all dissolved in $1 \mathrm{~mL}$ of water, using an ultrasonic bath. Two versions were studied, with and without addition of ionic liquid (IL). In the case of IL addition, $80 \mu \mathrm{L}$ was taken from the sensor cocktail and $2 \mu \mathrm{L}$ of the IL added and homogenised. The sensor preparation consists of casting the membrane on one side of a Mylar support (Goodfellow, Manchester, UK) from $20 \mu \mathrm{L}$ of the cocktail. After that, the support was left to dry in darkness in a box for $6 \mathrm{~h}$ at room temperature.

\subsection{Spectrophotometric measurement}

For the characterization of the sensing membranes, steady-state measurements were performed using a Hewlett Packard diode array 
spectrophotometer (model 8453; Nortwalk, CT, US) for absorption measurements. The measurements of the sensing films were performed using a homemade cell holder, so that the gas flux was directed to the sensing membrane.

\subsection{Colour measurement}

The membranes were imaged using a Sony DSC-HX300 digital camera (Japan) placed inside of a homemade wooden enclosure (see Fig. 1) illuminated with two LED-lamps $(6500 \mathrm{~K}$, illumination inside of the box $=9680 \mathrm{Lx}$ ) placed at $90^{\circ}$ with respect to the digital camera to minimise any interference from external light.

The optimised settings used to photograph the sensing membrane were ISO 80 , shutter speed $1 / 320 \mathrm{~s}$, aperture value $\mathrm{f} / 4$, focal distance $14 \mathrm{~mm}$; white balance, automatic; resolution, $3648 \times 2736$; mode, macro.

The hue or H component of the hue, saturation, value (HSV) colour space of the region of interest (ROI) of the membranes were determined using Image $\mathbf{J}$ software (National Institutes of Health) along with the Color Space Converter plugin to generate the median values of the $\mathrm{H}$ parameter from the pixels (around 153000) that compose the ROI. ROI is defined as the area of the digitalised membrane selected to perform the colorimetric analysis in order to get analytical information.

\subsection{Microbiology experiments}

Raw pork was purchased fresh from a butcher, packaged in $500 \mathrm{~g}$ quantities inside $\mathrm{CO}_{2} / \mathrm{O}_{2}$ impermeable bags, and sealed using an impulse bag sealer. The samples were stored at $4{ }^{\circ} \mathrm{C}$ and analysed over time for the presence of total aerobic count and members of the families Pseudomonadaceae and Enterobacteriaceae.

For the bacteriological analysis of packaged raw pork, $27 \mathrm{~g}$ of sample was weighed into a sterile petri dish using an aseptic technique, transferred into $243 \mathrm{~mL}$ of Buffered Peptone Water and ho-

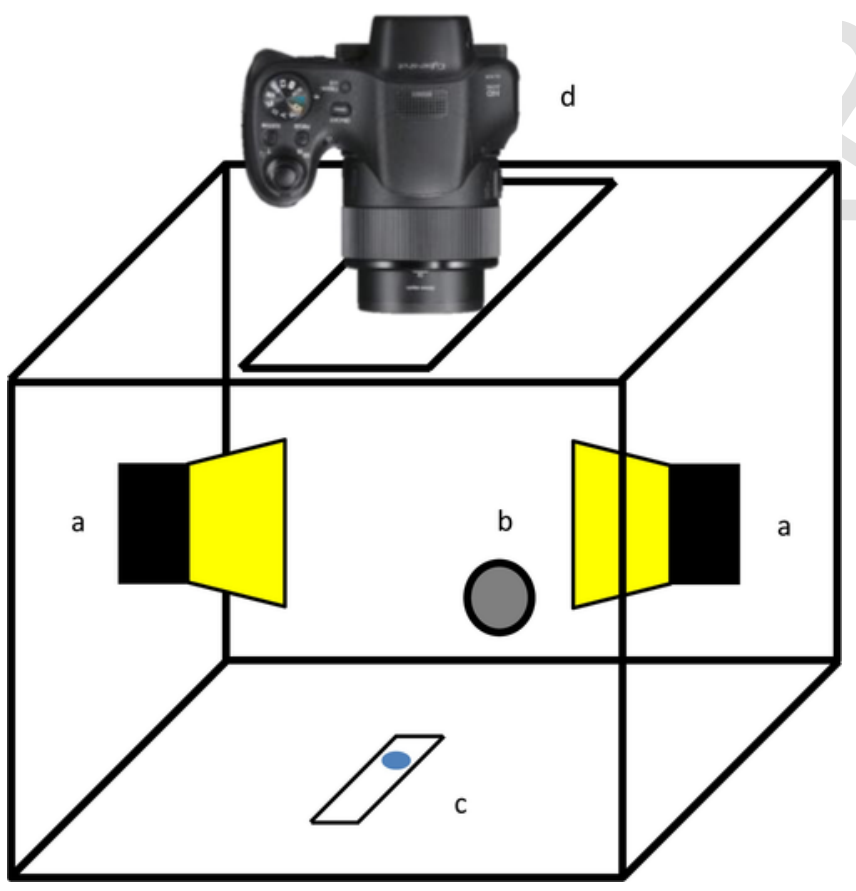

Fig. 1. Homemade light box used to digitalize the membranes. a) LED-lamps; b) gas inlet; c) membrane and d) digital camera. mogenised using a stomacher for $30 \mathrm{~s}$. Serial dilutions of $9 \mathrm{~mL}$ aliquots of Maximum Recovery Diluent were prepared and suitable dilutions were plated in triplicate and poured with plate count agar (PCA-Total aerobic count), Pseudomonad agar (Pseudomonads) and VRBA (Enterobacteriaceae). Plates were incubated as follows: PCA $22^{\circ} \mathrm{C}$ for $48 \mathrm{~h}$ and $37^{\circ} \mathrm{C}$ for $24 \mathrm{~h}$, pseudomonads $30^{\circ} \mathrm{C}$ for $24 \mathrm{~h}$ and VRBA $37^{\circ} \mathrm{C}$ for $24 \mathrm{~h}$. Following incubation plates were counted and the result expressed as numbers of organisms $/ \mathrm{g}$. pork.

\section{Results and discussion}

3.1. Correlation bacteria count versus concentration of $\mathrm{CO}_{2}$. bacteriological analysis of packaged raw pork

The intended use of this sensor is as a freshness indicator in pork meat, and therefore the first experiments carried out were performed in order to find out the concentrations of $\mathrm{CO}_{2}$ that can be correlated with the state of the packaged meat. In order to know the state of the meat, the correlation of the gases inside the package with bacteria present must be studied. Pseudomonas spp., Enterobacteriaceae [24] and TVC [25] (Total Viable Count) are key parameters to evaluate this. It has been accepted that $10^{7} \mathrm{cfu} / \mathrm{g} / \mathrm{mL}$ or $\mathrm{cm}^{2}$ is the threshold for indicating meat spoilage [26]. It has been previously demonstrated [14] that the increase in the percentage of $\mathrm{CO}_{2}$ in packaged food can be correlated with the freshness state in kimchi [27], pea and tomato soup [28], salads [13] and meat. Rukchon et al. found an increase in $\mathrm{CO}_{2}$ percentage in chicken breast during its spoilage [24], the experiments suggesting that chicken breasts stored at $4{ }^{\circ} \mathrm{C}$ remained stable for 6 days.

Therefore, the following experiments were carried out to correlate bacteria count versus concentration of $\mathrm{CO}_{2}$ for the new sensor. Each day of analysis, one of the stored meat packages was selected and before opening to perform the bacteriological analysis, the concentration of $\mathrm{CO}_{2}$ was measured by the Checkpoint analyser. Experiments were performed at days $0,2,5,7,9$, and 12. Fig. 2 shows the increase in $\mathrm{CO}_{2}$ and bacteria count over time.

The correlation between bacterial counts and gas release is clearly shows that from day 5 and the $\mathrm{CO}_{2}$ concentration rises above ca. $20 \%$ and simultaneously the bacterial count crosses the threshold of $10^{7}$ $\mathrm{cfu} / \mathrm{g} / \mathrm{mL}$ or $\mathrm{cm}^{2}$. It can be observed from Fig. 2 that the concentration of oxygen decreases until day 7 , at which point all oxygen has been used for bacterial growth, and from that day on the bacterial count and concentration of $\mathrm{CO}_{2}$ remain practically constant.

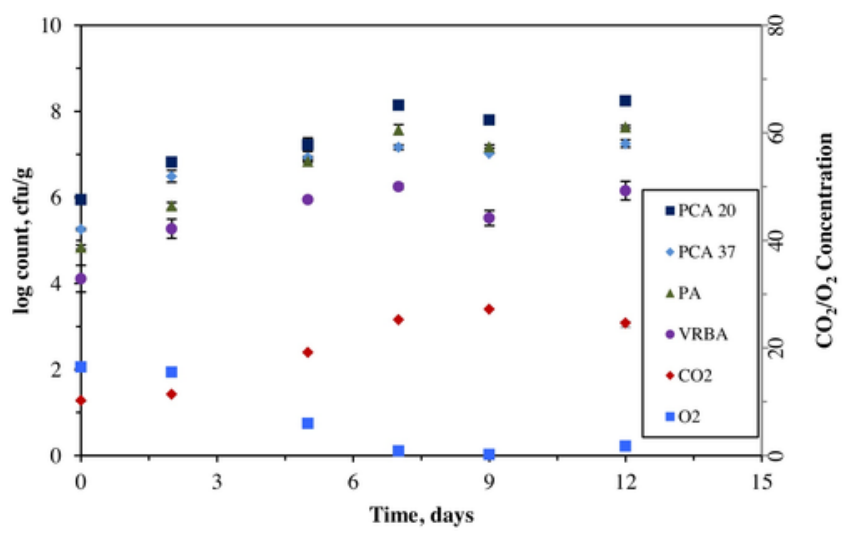

Fig. 2. Bacterial growth versus time (x axis) and $\mathrm{O}_{2} / \mathrm{CO}_{2}$ concentration $\left(\mathrm{y}_{2}\right.$ axis) inside packages. PCA 20 (Total aerobic count at $20^{\circ} \mathrm{C}$ ), PCA 37 (Total aerobic count at $\left.37^{\circ} \mathrm{C}\right)$, PA (Pseudomonads), VRBA (Enterobacteriaceae). 
It can be concluded from this experiment that the $\mathrm{CO}_{2}$ sensor should be highly sensitive for concentrations up to $20 \% \mathrm{CO}_{2}$ and the stability should be greater than 10 days ( 2 weeks). In this study, meat spoilage occurred after 5 days, but twice this period was selected for the sensor lifetime to cover extended meat lifetimes due to modified atmosphere packaging.

\section{2. $\mathrm{CO}_{2}$ sensing membrane characterisation}

The ideal sensor characteristics for this application encompass the following easily printable ink compatible with the food packaging process, sufficient sensitivity over the relevant $\mathrm{CO}_{2}$ concentration range ( $20 \%$ target concentration) and high stability, especially in ambient light.

The absorption spectrum of the $\mathrm{CO}_{2}$ sensor membranes was monitored by UV-vis absorption spectroscopy as a function of $\mathrm{CO}_{2}$ concentration, and exhibited two peak maxima; one at $420 \mathrm{~nm}$ that increases with $\mathrm{CO}_{2}$ concentration, and another at $595 \mathrm{~nm}$, that decreases with $\mathrm{CO}_{2}$ concentration, and together with an isosbestic point at $495 \mathrm{~nm}$, indicating the existence of an equilibrium between both dye forms (blue/yellow) with equal molar absorptivity at this wavelength.

Fig. 3 shows the response of the sensing membranes at different concentrations of $\mathrm{CO}_{2}$ ranging from 0 to $100 \%$ at $595 \mathrm{~nm}$. From this, the typical decay function of absorbance versus $\mathrm{CO}_{2}$ concentration can be obtained [31,32]. Fig. 3 shows the sensor sensitivity is higher at low concentrations of $\mathrm{CO}_{2}$, and as the threshold established by

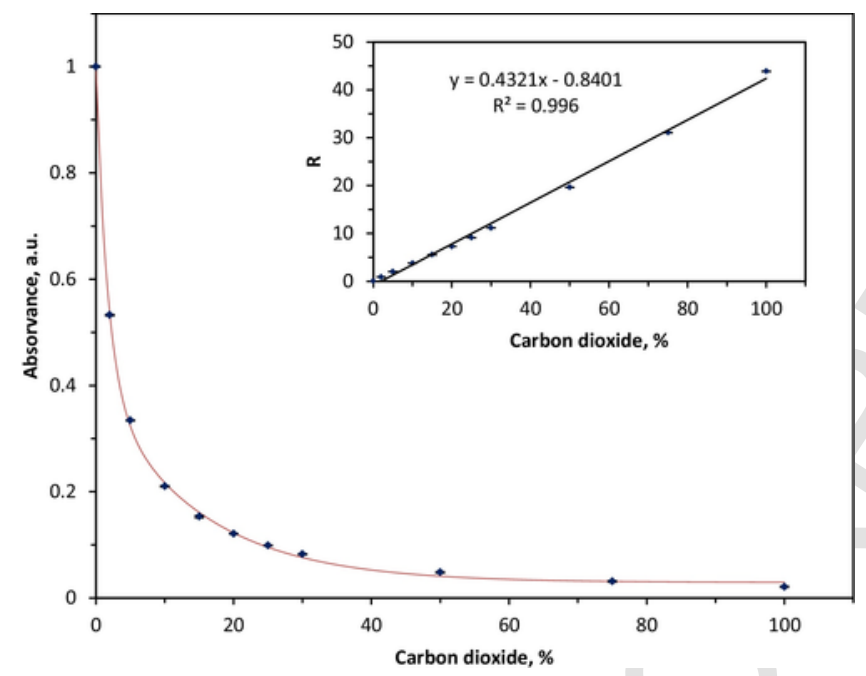

Fig. 3. Absorbance at $595 \mathrm{~nm}$ versus $\mathrm{CO}_{2}$ concentration from 0 to $100 \%$. Inset. R versus the concentration of $\mathrm{CO}_{2}$ bacteriological analysis was around $20 \%$ the composition of the cocktail has been optimised to maintain a high sensitivity at low concentrations of $\mathrm{CO}_{2}$. This depends on the kind of modified atmosphere used for the packaged food as, if high concentrations of $\mathrm{CO}_{2}$ are used, the sensitivity of the $\mathrm{CO}_{2}$ sensor should be moved towards higher concentrations. In this example, no modified atmosphere has been used and $20 \%$ is the preferred threshold for detection.

In order to obtain a linear function, the parameter $\mathrm{R}$ can be described as the ratio of the concentrations of the protonated to deprotonated forms of the indicator [32] and calculated using the absorbance at $0 \%$ of $\mathrm{CO}_{2}\left(\mathrm{~A}_{\mathrm{o}}\right)$, at $100 \%$ of $\mathrm{CO}_{2}\left(\mathrm{~A}_{\infty}\right)$ and at any intermediate value measured at the wavelength of the maximum for deprotonated indicator (Eq. (6)).

$$
R=\frac{A_{o}-A}{A-A_{\infty}}=\frac{[H I n]}{\left[I n^{-}\right]}
$$

If $\mathrm{R}$ is plotted versus the concentration of $\mathrm{CO}_{2}$, a straight line is obtained that confirms the reaction ratio $1: 1$ between $\mathrm{CO}_{2}$ and $\mathrm{MCP}$.

The inclusion of the IL 1-ethyl-3-methyl-imidazolium chloride is key in making the sensor more selective to $\mathrm{CO}_{2}$ than other gases due higher $\mathrm{CO}_{2}$ solubility [33] which reduces the response and recovery times of the sensor. A study of the dynamic response of the sensing membranes when exposed to alternating atmospheres of pure $\mathrm{CO}_{2}$ and pure $\mathrm{N}_{2}$ was carried out. The response time was calculated from between $10 \%$ and $90 \%$ of the maximum signal. Table 1 shows the differences between the dynamic behaviour of sensing membranes having IL or not in their matrix.

As can be observed in Fig. 4. A and B, the response and recovery times are much quicker in the case $\mathrm{A}$ than $\mathrm{B}$, where a membrane containing IL has been used.

The limit of detection (LOD) was calculated from the calibration function (inset Fig. 3), by using the conventional approach defined by $\mathrm{LOD}=\mathrm{R}_{0}+3 \mathrm{~s} 0$, where $\mathrm{R}_{0}$ is the blank or average value in the absence of $\mathrm{CO}_{2}$ and $\mathrm{s}_{0}$ is the critical level or standard deviation of the blank, which was determined from six replicate measurements. The limit of quantification (LOQ) of the instrumental procedure was obtained by using $\mathrm{LOQ}=\mathrm{R}_{0}+10 \mathrm{~s}_{0}$. The LOD found by using this approach was $0.36 \% \mathrm{CO}_{2}$ and the LOQ was $0.37 \% \mathrm{CO}_{2}$.

Table 1

Response and recovery times of sensing membranes containing (A) and not containing IL (B). $n=3$.

\begin{tabular}{llll}
\hline Membrane containing IL (A) & \multicolumn{3}{l}{ Membrane no containing IL (B) } \\
\hline Response Time & Recovery Time & Response Time & Recovery Time \\
$17 \pm 1 \mathrm{~s}$ & $105 \pm 4 \mathrm{~s}$ & $530 \mathrm{~s} \pm 20 \mathrm{~s}$ & $540 \mathrm{~s} \pm 32$ \\
\hline
\end{tabular}

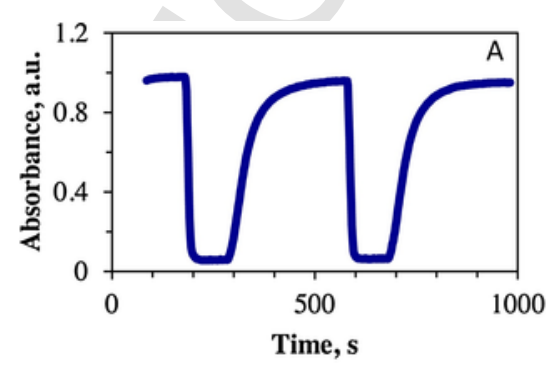

Fig. 4. Dynamic behaviour of sensing membranes. (A) containing IL (B) without IL. 


\subsection{Humidity dependence}

Given the intended application of the sensor, high relative humidity is expected in the packaged meat so dependence to humidity must be studied. A serial of calibrations were carried out in triplicate from 0 to $100 \%$ of RH (Fig. 5). As can be observed from Fig. 5 the dependence is not very high compared to other $\mathrm{CO}_{2}$ sensors [16]. In fact, the response is only slightly unaffected (the slope of the calibration function varies between 0.1864 and 0.235 ), and this can be explained by the use of the ionic liquid in the sensor matrix. If the sensitivity (as slope of calibration function) is plotted versus the concentration of $\mathrm{CO}_{2}$ (Fig. 6) a slight decrease is observed when the relative humidity increases, but it is a really small change (slope $=-0.0005 / \% \mathrm{RH}$ ). However, it does affect the sensor stability (see following section).

\subsection{Stability of sensing membrane}

The stability of the sensor is a crucial variable for maximizing the duration of service and is a key factor in its future application. The application in meat packages for the food industry requires at least 2 weeks lifetime to be implemented in real situations. Different environments were studied using a set of three sensors for each experiment: a) conventional light conditions, RT (room temperature), b) darkness, RT and high humidity, c) darkness and RT d) darkness high humidity and $4{ }^{\circ} \mathrm{C}$. The results are summarised in Table 2 . It can be concluded from this set of experiments that light does not signifi-

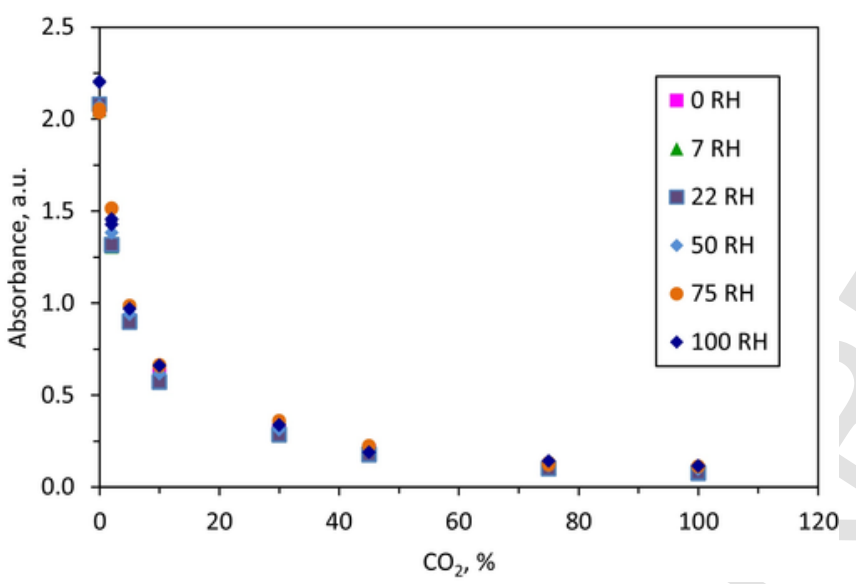

Fig. 5. Absorbance versus $\mathrm{CO}_{2}$ concentration at different values of $\mathrm{RH}$.

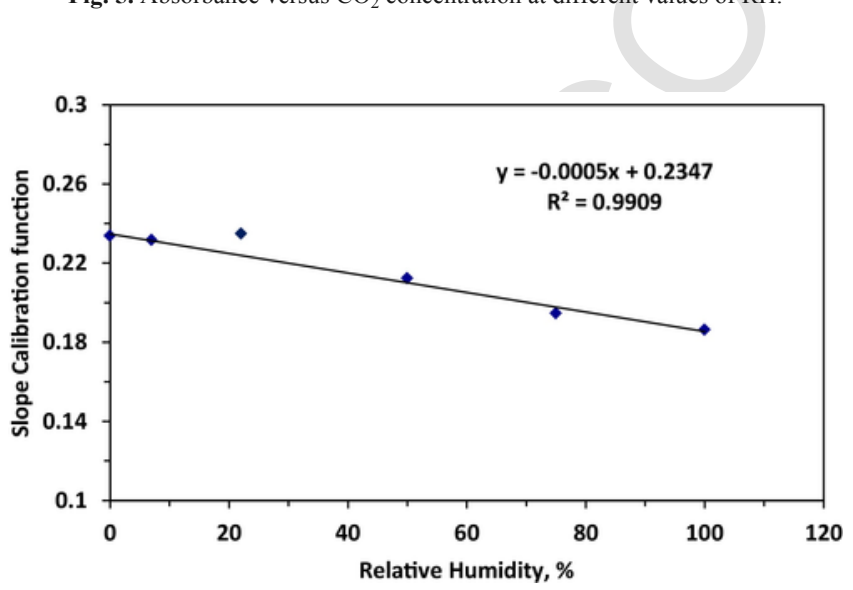

Fig. 6. Sensitivity of calibration functions obtained at different percentages of RH.
Table 2

Summary of lifetime of the $\mathrm{CO}_{2}$ sensor under different conditions.

\begin{tabular}{ll}
\hline Conditions & Stability \\
\hline Conventional light conditions, RT & 1 month \\
Darkness, RT & 1 month \\
High relative humidity, darkness and RT & 1 week \\
High relative humidity, darkness and $4{ }^{\circ} \mathrm{C}$ & 2 months \\
\hline
\end{tabular}

cantly affect the performance of the sensor, and is much less compared to solvent based sensors for $\mathrm{CO}_{2}[16,20,34]$. Actually, there is no observable difference for sensors kept under ambient light conditions and those kept in darkness. However, relative humidity has a high effect on the stability of the sensor, but high relative humidity together with low temperature does not appreciably affect the stability of the sensor, and under these conditions it can perform satisfactorily for more than 2 weeks (i.e. the stability required for the intended application can be met under the storage conditions typically used).

The stability durations shown in Table 2 have been calculated for the sensors stored under the same conditions through the entire study. After the stability duration is exceeded, the sensor calibration function starts to change (becomes curved), so the sensors still respond to $\mathrm{CO}_{2}$ over the whole range, but with different sensitivity. The criterion for stability is that the slope of the calibration function changes by more than $10 \%$ from the original calibration on day 1 . is a variability of the slope of the calibration function less than $10 \%$.

Calibrations were carried out twice a week during the whole period studied for each set of membranes kept under the different conditions studied. Fig. 7 shows the calibration function for each set of experiments. Each calibration function shown is representative of the entire stable lifetime.

The stability of sensor is a key parameter as this will define its applicability. Often in the literature, such sensors are kept under special storage conditions such as in desiccators and under specially controlled humidity or light conditions. But if the sensor is intended for real applications, more realistic storage conditions should be studied. Table 3 shows the stability shown for different $\mathrm{CO}_{2}$ sensors found in literature.

\subsection{Applicability}

The intended application of this sensor is as freshness indicator that could be monitored using a simple digital camerawith the ultimate aim to create an Android application that could be implemented in a mobile phone.

The hue or H component of the hue, saturation, value (HSV) colour space is calculated here instead the well-known and often used RGB coordinates, due to. The reason why the $\mathrm{H}$ is selected is because the robust nature and superior precision when tracking colour changes in digital images. This parameter has been demonstrated to be 2-3 times superior than RGB, due to small variations in signal with indicator concentration, membrane thickness, detector spectral responsivity, and illumination [36,37].

Calibration functions were carried out at different concentrations of $\mathrm{CO}_{2}$ and pictures were taken at each concentration. Images were analysed using the program ImageJ and the hue $(\mathrm{H})$ coordinate calculated. Fig. 8. shows the colours obtained at different concentration of $\mathrm{CO}_{2}$ and Fig. 9 the $\mathrm{H}$ coordinate versus the percentage of $\mathrm{CO}_{2}$.

Data can be fitted to an exponential growth function (red line), which returns the following equation $y=-0.49705 \frac{x}{-7.76348}+1.16483, r^{2}=0.99015$. Results obtained are in concordance agreement with the those obtained using the Spectrophotometer, with higher changes at low $\mathrm{CO}_{2}$ concentrations and 

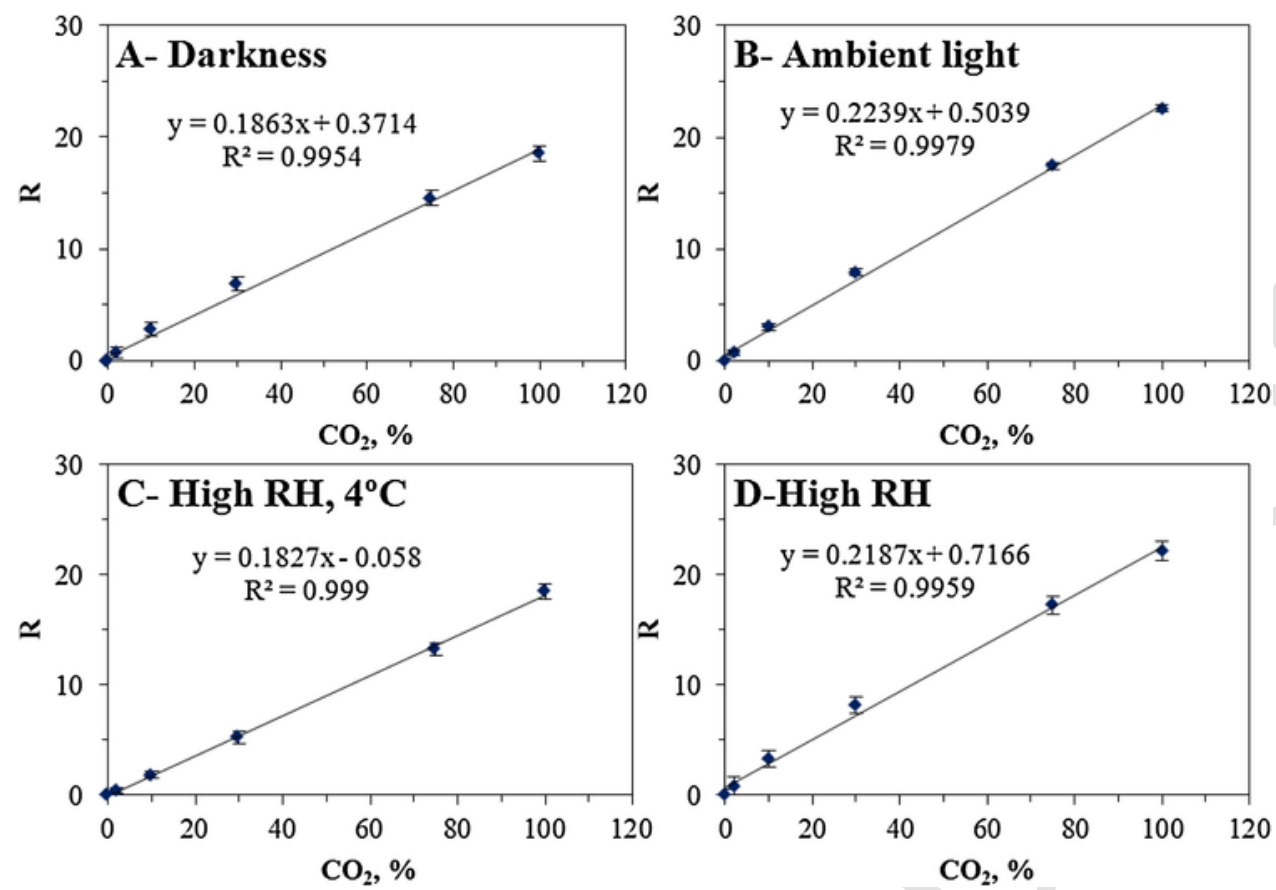

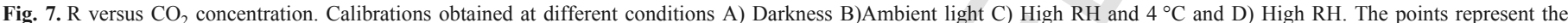
average of all measurements across respective $\mathrm{CO}_{2}$ concentrations, error bars are the standard deviation, and a linear fit is given as the black lines.

smaller changes at high $\mathrm{CO}_{2}$ concentrations. At $20 \%$ of $\mathrm{CO}_{2}$ the signal is ca. $90 \%$ of the total response of the $\mathrm{H}$ value.

\section{Conclusions}

The work documented in this paper has detailed the development of a $\mathrm{CO}_{2}$ sensor based on a colorimetric membrane incorporating an IL and targeting applications in the food industry (pork meat). The inclusion of an ionic liquid in the matrix improves the dynamic response. This sensor was studied using a spectrophotometer and a digital camera, with the latter showing a strong correlation between gas concentration and hue coordinate. This represents the basis of a smartphone based detection system that could be used by consumers and food industry workers. A study related to the correlation between the gas generated by pork meat over time versus the total bacteria count identified $20 \%$ of $\mathrm{CO}_{2}$ as the threshold for indicating pork meat spoilage in unmodified atmosphere packaged samples. The feasibility of this new sensor was studied under different conditions showing that at high humidity and $4{ }^{\circ} \mathrm{C}$ (conditions of commercialised packed meat) a stability of more than two weeks was obtained, which meets the requirements for the intended application.

\section{Acknowledgements}

This work was supported by Talentia Postdoc Program launched by the Andalusian Knowledge Agency, co-funded by the European Union's Seventh Framework Program, Marie Skłodowska-Curie actions (COFUND - Grant Agreement $n^{\circ}$ 267226) and the Ministry of Economy, Innovation, Science and Employment of the Junta de Andalucía. Support from the Science Foundation Ireland INSIGHT Centre for Data Analytics is greatly acknowledged (Grant Number $\mathrm{SFI} / 12 / \mathrm{RC} / 2289$ ). The authors would like to express their gratitude to Angel Barros from Sealed Air for his valuable advice on materials for the food industry. 
Table 3

Examples of $\mathrm{CO}_{2}$ sensor found in literature.

\begin{tabular}{|c|c|c|c|c|}
\hline $\begin{array}{l}\text { Type of } \\
\text { measurement }\end{array}$ & $\begin{array}{l}\text { Components of } \\
\text { the membrane }\end{array}$ & $\begin{array}{l}\text { Storage } \\
\text { conditions }\end{array}$ & Lifetime & Reference \\
\hline \multirow[t]{4}{*}{ Absorbance } & \multirow[t]{4}{*}{$\begin{array}{c}\mathrm{MCP}, \mathrm{NaHCO}_{3}, \\
\mathrm{HEC}, \mathrm{Gly}, \mathrm{IL}\end{array}$} & Ambient light & 30 days & \multirow[t]{4}{*}{$\begin{array}{l}\text { Current } \\
\text { study }\end{array}$} \\
\hline & & Darkness & 30 days & \\
\hline & & High RH & 7 days & \\
\hline & & $\begin{array}{l}\text { High RH, } \\
4^{\circ} \mathrm{C}\end{array}$ & 60 days & \\
\hline \multirow[t]{4}{*}{ Phosphorescence } & $\begin{array}{l}\text { TBP, } \alpha-\mathrm{NP}, \\
\text { TMAOH, EC }\end{array}$ & Darkness & 515 days & \multirow[t]{4}{*}[35]{} \\
\hline & $\begin{array}{l}\text { TBP, } \alpha-\mathrm{NP}, \\
\text { TMAOH, } \\
\text { DBU }\end{array}$ & & 20 days & \\
\hline & $\begin{array}{l}\text { TBP, } \alpha-\mathrm{NP} \\
\text { TMAOH, } \\
\text { HPMC }\end{array}$ & & 390 days & \\
\hline & $\begin{array}{l}\alpha-\mathrm{NP}, \mathrm{TMAOH}, \\
\text { HPMC, } \\
\text { TWEEN } 20\end{array}$ & & 300 days & \\
\hline \multirow[t]{3}{*}{ Phosphorescence } & $\begin{array}{l}\text { PtTFPP, } \alpha-\mathrm{NP}, \\
\text { CTAOH, EC }\end{array}$ & $4{ }^{\circ} \mathrm{C}$ & 14 days & \multirow[t]{3}{*}[13]{} \\
\hline & & RT & 7 days & \\
\hline & & $4^{\circ} \mathrm{C}$ and $\mathrm{MA}$ & 21 days & \\
\hline Absorbance & $\begin{array}{l}\text { MCP, HEC, } \\
\text { Gly, NaHCO3 }\end{array}$ & $\begin{array}{l}\text { Laboratory } \\
\text { conditions }\end{array}$ & $\begin{array}{l}\text { After } 21 \text { days } \\
\text { starts to fade }\end{array}$ & {$[16]$} \\
\hline \multirow[t]{3}{*}{ Phosphorescence } & \multirow[t]{3}{*}{$\begin{array}{l}\text { PtOEP, } \alpha-\mathrm{NP}, \\
\text { TOAOH, EC }\end{array}$} & $33 \% \mathrm{RH}$ & $\begin{array}{l}\text { Half-signal 4-7 } \\
\text { days }\end{array}$ & \multirow[t]{3}{*}[20]{} \\
\hline & & $\begin{array}{l}95 \% \mathrm{RH}+ \\
\text { light }\end{array}$ & $\begin{array}{l}\text { Half-signal 4-7 } \\
\text { days }\end{array}$ & \\
\hline & & $\begin{array}{c}95 \% \mathrm{RH}+ \\
\text { darkness }\end{array}$ & $\begin{array}{l}\text { Half-signal } 11 \\
\text { months }\end{array}$ & \\
\hline Fluorescence & $\begin{array}{l}\text { HTPS, EC, } \\
\text { EMIMBF4 }\end{array}$ & $\begin{array}{c}\text { Laboratory } \\
\text { conditions }\end{array}$ & $\begin{array}{l}\text { Lost in signal by } \\
10-24 \% \text { after } \\
95 \text { days }\end{array}$ & {$[23]$} \\
\hline Fluorescence & $\begin{array}{l}\text { HTPS, EC, } \\
\text { TOAOH }\end{array}$ & $\begin{array}{l}\text { Desiccator + } \\
\text { Sodium } \\
\text { carbonate }\end{array}$ & $\begin{array}{l}16,2 \% \text { signal } \\
\text { drift after } \\
5 \text { days }\end{array}$ & {$[31]$} \\
\hline
\end{tabular}

tetramethylammonium, EC: Ethylcellulose, DBU: 1,8-diazabicyclo[5.4.0]undec-7-ene, HPMC: MethocelE-5 Premium, PtTFPP: Pt-porphyrin, CTAOH: cetyltrimethylammonium hydroxide, PtOEP: Pt- Octaethyl porphyrin, HPTS, EMIMBF4: 1-ethyl-3-methylimidazolium tetrafluoroborate.

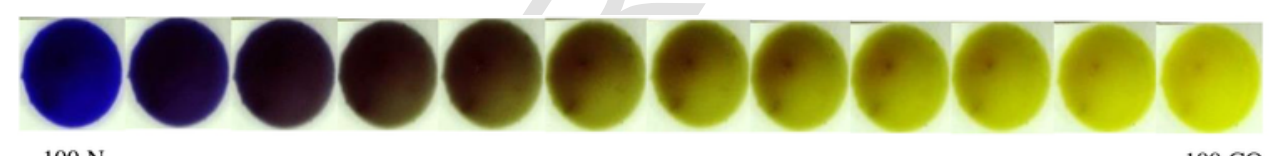

$100 \mathrm{~N}_{2}$

$100 \mathrm{CO}_{2}$

Fig. 8. Photographs of sensing membranes from $100 \mathrm{~N}_{2}$ to $100 \mathrm{CO}_{2}$. 


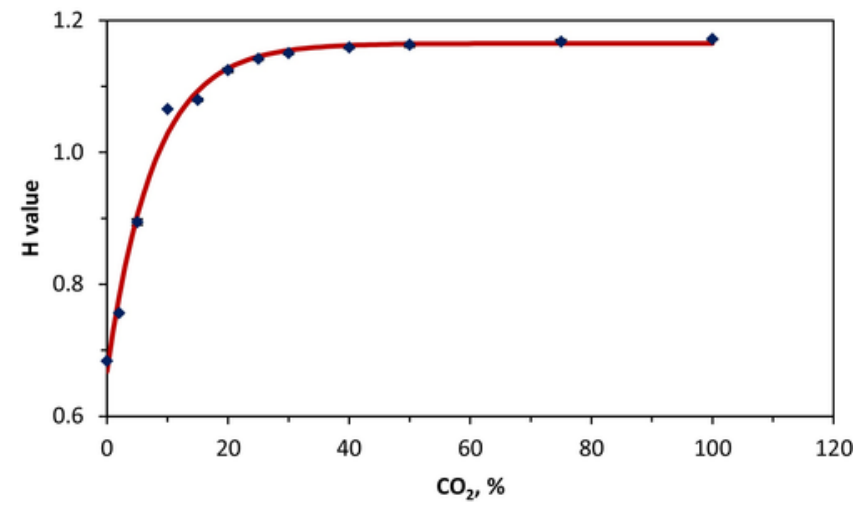

Fig. 9. $\mathrm{H}$ value versus $\mathrm{CO}_{2}$ concentration, $\mathrm{n}=3$.

\section{References}

[1] H.M. Ertugrul, M. Cetin, F. Seker, E. Dogan, The impact of trade openness on global carbon dioxide emissions: evidence from the top ten emitters among developing countries, Ecol. Indic. 67 (2016) 543-555.

[2] V. Rimpilä, K. Hosokawa, H. Huhtala, T. Saaresranta, A.V. Salminen, O. Polo, Transcutaneous carbon dioxide during sleep-disordered breathing, Respir. Physiol. Neurobiol. 219 (2015) 95-102.

[3] H. Kaya, O. Hisar, S. Yılmaz, M. Gürkan, A.Ş. Hisar, The effects of elevated carbon dioxide and temperature levels on tilapia (Oreochromis mossambicus): Respiratory enzymes, blood $\mathrm{pH}$ and hematological parameters, Environ. Toxicol. Pharmacol. 44 (2016) 114-119.

[4] S.A. Deviren, B. Deviren, The relationship between carbon dioxide emission and economic growth: hierarchical structure methods, Physica A 451 (2016) 429-439.

[5] D. Haigh-Flórez, C. Cano-Raya, M. Bedoya, G. Orellana, Rugged fibre-optic luminescent sensor for $\mathrm{CO} 2$ determination in microalgae photoreactors for biofuel production, Sens. Actuators B 221 (2015) 978-984.

[6] A. Mendes, S. Bonassi, L. Aguiar, C. Pereira, P. Neves, S. Silva, et al., Indoor air quality and thermal comfort in elderly care centers, Urban Clim. 14 (Part 3) (2015) 486-501.

[7] I.P.M.W. Group, Solutions Carbon Dioxide Treatment, Controlled Atmosphere Carbon Dioxide Treatment, 2008.

[8] The Structural Conservation of Panel Paintings: Proceedings of a Symposium at the J. Paul Getty Museum, in: K.D.a.A. Rothe (Ed.)1998, pp. 305-565.

[9] A. Valdez Fragoso, H. Mújica-Paz, Controlled atmosphere storage: effect on fruit and vegetables, Encyclopedia of Food and Health, Academic Press, Oxford, 2016308-311.

[10] J.P. Kerry, M.N. O'Grady, S.A. Hogan, Past, current and potential utilisation of active and intelligent packaging systems for meat and muscle-based products: a review, Meat Sci. 74 (2006) 113-130.

[11] F. Zouaghi, M.J. Cantalejo, Study of modified atmosphere packaging on the quality of ozonated freeze-dried chicken meat, Meat Sci. 119 (2016) 123-131.

[12] M. Perna, Modified Atmosphere Packaging of Fresh Meat, Reference Module in Food, Elsevier, 2016.

[13] N.B. Borchert, J.P. Kerry, D.B. Papkovsky, A CO2 sensor based on Pt-porphyrin dye and FRET scheme for food packaging applications, Sens. Actuators B 176 (2013) 157-165.

[14] P. Puligundla, J. Jung, S. Ko, Carbon dioxide sensors for intelligent food packaging applications, Food Control 25 (2012) 328-333.

[15] O.S. Wolfbeis, Fiber-optic chemical sensors and biosensors, Anal. Chem. 80 (2008) 4269-4283.

[16] A. Mills, G.A. Skinner, Water-based colourimetric optical indicators for the detection of carbon dioxide, Analyst 135 (2010) 1912-1917.

[17] R. Ali, T. Lang, S.M. Saleh, R.J. Meier, O.S. Wolfbeis, Optical sensing scheme for carbon dioxide using a solvatochromic probe, Anal. Chem. 83 (2011) 2846-2851.

[18] I.M. Pérez de Vargas-Sansalvador, C. Fay, T. Phelan, M.D. Fernández-Ramos, L.F. Capitán-Vallvey, D. Diamond, et al., A new light emitting diode-light emitting diode portable carbon dioxide gas sensor based on an interchangeable membrane system for industrial applications, Anal. Chim. Acta 699 (2011) 216-222.

[19] C.S. Burke, A. Markey, R.I. Nooney, P. Byrne, C. McDonagh, Development of an optical sensor probe for the detection of dissolved carbon dioxide, Sens. Actuators B 119 (2006) 288-294.

[20] M.A. Carvajal, I.M.P. de Vargas-Sansalvador, A.J. Palma, M.D. Fernández-Ramos, L.F. Capitán-Vallvey, Hand-held optical instrument for CO2 in gas phase based on sensing film coating optoelectronic elements, Sens. Actuators B 144 (2010) 232-238.

[21] I.M. Pérez de Vargas-Sansalvador, M.A. Carvajal, O.M. Roldán-Muñoz, J. Banqueri, M.D. Fernández-Ramos, L.F. Capitán-Vallvey, Phosphorescent sensing of carbon dioxide based on secondary inner-filter quenching, Anal. Chim. Acta 655 (2009) 66-74.

[22] O. Oter, K. Ertekin, D. Topkaya, S. Alp, Room temperature ionic liquids as optical sensor matrix materials for gaseous and dissolved CO2, Sens. Actuators B 117 (2006) 295-301.

[23] O. Oter, K. Ertekin, S. Derinkuyu, Ratiometric sensing of CO2 in ionic liquid modified ethyl cellulose matrix, Talanta 76 (2008) 557-563.

[24] C. Rukchon, A. Nopwinyuwong, S. Trevanich, T. Jinkarn, P. Suppakul, Development of a food spoilage indicator for monitoring freshness of skinless chicken breast, Talanta 130 (2014) 547-554.

[25] L. Huang, J. Zhao, Q. Chen, Y. Zhang, Rapid detection of total viable count (TVC) in pork meat by hyperspectral imaging, Food Res. Int. 54 (2013) $821-828$.

[26] R. Gutierrez, T. Garcia, I. Gonzalez, B. Sanz, P.E. Hernandez, R. Martin, Quantitative detection of meat spoilage bacteria by using the polymerase chain reaction (PCR) and an enzyme linked immunosorbent assay (ELISA), Lett. Appl. Microbiol. 26 (1998) 372-376.

[27] S.-I. Hong, W.-S. Park, Use of color indicators as an active packaging system for evaluating kimchi fermentation, J. Food Eng. 46 (2000) 67-72.

[28] T. Mattila, R. Ahvenainen, Preincubation time and the use of oxygen indicators in determining the microbiological quality of aseptically packed pea and tomato soup, Int. J. Food Microbiol. 9 (1989) 205-214.

[29] Y. Amao, N. Nakamura, An optical sensor with the combination of colorimetric change of $\alpha$-naphtholphthalein and internal reference luminescent dye for $\mathrm{CO} 2$ in water, Sens. Actuators B 107 (2005) 861-865.

[30] A. Calvo-López, O. Ymbern, D. Izquierdo, J. Alonso-Chamarro, Low cost and compact analytical microsystem for carbon dioxide determination in production processes of wine and beer, Anal. Chim. Acta 931 (2016) 64-69.

[31] K. Ertekin, I. Klimant, G. Neurauter, O.S. Wolfbeis, Characterization of a reservoir-type capillary optical microsensor for $\mathrm{pCO} 2$ measurements, Talanta 59 (2003) 261-267.

[32] A. Mills, Q. Chang, N. McMurray, Equilibrium studies on colorimetric plastic film sensors for carbon dioxide, Anal. Chem. 64 (1992) 1383-1389.

[33] M.G. Freire, L.M.N.B.F. Santos, A.M. Fernandes, J.A.P. Coutinho, I.M. Marrucho, An overview of the mutual solubilities of water-imidazolium-based ionic liquids systems, Fluid Phase Equilib. 261 (2007) 449-454.

[34] G. Neurauter, I. Klimant, O.S. Wolfbeis, Microsecond lifetime-based optical carbon dioxide sensor using luminescence resonance energy transfer, Anal. Chim. Acta 382 (1999) 67-75.

[35] M.L. Aguayo-López, L.F. Capitán-Vallvey, M.D. Fernández-Ramos, Optical sensor for carbon dioxide gas determination, characterization and improvements, Talanta 126 (2014) 196-201.

[36] K. Cantrell, M.M. Erenas, I. de Orbe-Payá, L.F. Capitán-Vallvey, Use of the hue parameter of the hue, saturation, value color space as a quantitative analytical parameter for bitonal optical sensors, Anal. Chem. 82 (2010) 531-542.

[37] M.M. Erenas, K. Cantrell, J. Ballesta-Claver, I. de Orbe-Payá, L.F. Capitán-Vallvey, Use of digital reflection devices for measurement using hue-based optical sensors, Sens. Actuators B 174 (2012) 10-17.

Isabel M. Perez de Vargas Sansalvador received her B.Sc. in Chemistry (2005), M.Sc. (2008) and Ph.D. in Analytical Chemistry (2011) from the University of Granada (Spain). Her postdoctoral experience started at Cranfield University (UK) and later at Dublin City University (Ireland). She is currently a Marie Curie Fellow at the University of Granada. Her research interests include chemical sensors for environmental and food analysis applications.

Miguel M. Erenas was born in 1981 in Granada (Spain). He received the MSc degree (2006) and the PhD degree in Analytical Chemistry (2011) from the University of Granada (Granada, Spain). He is currently working as a researcher at the ECsens group, Department of Analytical Chemistry, University of Granada and his research interests include the use of imaging along with disposable sensors, and their applications to handheld instrumentation

Dermot Diamond received his Ph.D. and D.Sc. from Queen's University Belfast (Chemical Sensors, 1987, Internet Scale Sensing, 
2002), and was Vice-President for Research at Dublin City University (2002-2004). He has published over 300 peer-reviewed papers in international journals, is a named inventor in 18 patents, and is co-author and editor of four books. He was director (2007-2015) and founding member of the National Centre for Sensor Research (www.ncsr.ie) at Dublin City University, and is currently an SFI-funded investigator in the INSIGHT Centre (http://www.insight-centre.org).

Brid Quilty is a microbiologist and has worked in the area of Environmental Microbiology for more than 30 years. She leads the Microbial Ecology Group at Dublin City University and has a particular interest in the microbiology of food and water. Her work with the solar disinfection of water has led to her involvement with international projects in countries in the developing world including Bangladesh, Uganda, Malawi, Ethiopia and Brazil. She works in collaboration with industry on the development of novel biological approaches to the treatment of waste streams. She is currently the external representative on the Biological Safety Committee, Bristol Myers Smith, Cruisrath, Dublin, Ireland.

Luis Fermín Capitan-Vallvey, full Professor of Analytical Chemistry at the University of Granada, received his BSc in Chemistry (1973) and PhD in Chemistry (1986) from the Faculty of Sciences, University of Granada (Spain). In 1983, he founded the Solid Phase Spectrometry group (GSB) and in 2000, together with Prof. Palma López, the interdisciplinary group ECsens, which includes Chemists, Physicists and Electrical and Computer Engineers at the University of Granada. His current research interests are the design, development and fabrication of sensors and portable instrumentation for environmental, health and food analysis and monitoring. Currently is interested in printed chemical sensors and capillary-based microfluidic devices. 